\title{
Urban food insecurity: A neglected public health challenge
}

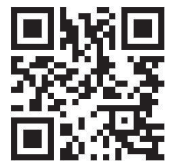

Our current way of eating makes us ill, divides us, and harms our planet. The health burden of our current diet is considerable, and there is increasing evidence that it is not environmentally or socially sustainable. ${ }^{[1,2]}$ Yet food and nutrition continue to receive little attention in health policy and professional training, locally and internationally. This is particularly true when the urban scale is considered. National food security and nutrition policy focuses disproportionately on rural populations. We argue that a revitalised public health agenda focusing on the conditions that shape what we eat would have significant benefits for current and future generations of South Africans. This has implications for how we educate the future generation of medical and healthcare professionals in South Africa (SA).

The 2012 South African National Health and Nutrition Examination Survey (SANHANES-1) ${ }^{[3]}$ indicated that diet-related noncommunicable diseases (NCDs) are widespread in the SA population. One in four adults had abnormal cholesterol levels, and 1/5 had impaired glucose homeostasis. Obesity among women increased from $27 \%$ in 2003 to $39.2 \%$ in 2012. Among children, overweight has increased from $10 \%$ to $18 \%$ since 2005 , while obesity has stabilised below 5\%. ${ }^{[3]}$ These increases in obesity are not uniform across the country, with obesity levels increasing at a faster rate in urban than rural areas. ${ }^{[4,5]}$ At the same time, chronic malnutrition, as measured in low height for age among children 0 - 3 years (the age group in which linear growth is most closely associated with other developmental markers) remains above $25 \%$. Micronutrient status, notably vitamin A and iron deficiency anaemia, has improved, but the vitamin A status of young children remains a significant public health problem. Nationally $45.6 \%$ of households were food secure, but this figure fell to $31.5 \%$ in urban informal areas and $30.2 \%$ in rural informal areas. At the same time, low dietary diversity, high fat and sugar intakes, and low consumption of fruit and vegetables were widespread. ${ }^{[3]}$

While hunger and chronic malnutrition persist, these findings confirm that SA has made the 'nutrition transition'- the shift towards a diet high in saturated fats, sugar and refined foods and low in fibre - particularly in urban areas. ${ }^{[6,7]}$ Further evidence of the dramatic changes in the SA diet over the last decades include the rise in sales of snack bars, ready meals and noodles by over $40 \%$ between 2005 and 2010 and the increased consumption of Coca Cola products from an already high 130 per person per year in 1992, to 254 per person per year in $2010 .^{[8]}$

The economic cost of undernutrition, to individuals and societies, is widely acknowledged, but there is now also growing evidence that NCDs associated with poor diets contribute to poverty and slow economic growth. ${ }^{[9]}$

The consequences of the food system for human health are increasingly apparent. At the same time, the health of the planet is also affected by our current diet. Globally, the trend is towards higher demand for processed and animal-based foods, as populations urbanise and average incomes rise. The negative environmental impact of the industrialised food system - including pollution due to nutrient run-off, biodiversity loss, water shortages, and greenhouse gas emissions - is not fully reflected in current food prices. ${ }^{[10]}$

The response to the nutrition challenge has tended to view under- and overnutrition as two separate issues. In the case of undernutrition, the focus is on direct interventions, such as promotion of breastfeeding, and vitamin A supplementation. Industry-focused regulatory policies include flour fortification with essential vitamins and minerals (which seems to have had a salutary effect on anaemia and vitamin A status in adults), ${ }^{[3]}$ and the recent endorsement of the international code on marketing of breast milk substitutes. The policy response to household food insecurity includes the social grant system and efforts to boost household food production with the distribution of 'starter-packs. ${ }^{\text {[1] }}$

Overnutrition has tended be framed as the result of poor personal choices (see, for example, the recent comments by Jamie Oliver on food choice in the UK). ${ }^{[12]}$ Responses to overnutrition therefore focus largely on nutrition education and the promotion of healthier foods. The recent interventions by the Minister of Health regarding the regulation of levels of salt in prepared foods, and endorsement of a nationwide campaign to reduce salt consumption, are evidence of the state's commitment to address the health consequences of poor diet.

However, we believe that a more comprehensive reframing of the public health nutrition agenda is necessary to create favorable conditions for healthy and sustainable eating. This will require a holistic conceptualisation of the physical and biological, psychosocial, and institutional dimensions that shape the environment in which food choices are made. A focus on individual and household level behaviour change, or on 'choice-editing' by retailers and regulations that address single foods or nutrients, will have limited impact. Under- and overnutrition are both connected to structural challenges in the food system. Policy responses and individual health practitioner interventions need to be informed by an understanding of the role that the structural issues in the food and wider social system play in shaping individual food consumption.

Dietary shifts have been linked to a number of factors, most noticeably higher urban incomes. However, work by Drewnowski and Popkin ${ }^{[6]}$ suggest that changing diets cannot only be attributed to higher average urban incomes. We also need to consider the macrogeography of the city, the local food environment, the household asset base and how these interact to shape consumption habits.

SA cities are shaped by their colonial and apartheid histories. By design the lowest income households continue to be located on the peripheries of the cities. This urban geography influences food insecurity in several ways. Firstly, it shapes economic opportunities and the potential to earn income for residents of low-income areas. In a market economy, income is a major driver of food security. Low-income earners, living long distances from jobs and facing inadequate public transport, have lengthy commutes and spend a large proportion of their incomes on transport, leaving less money to buy food. With limited time, and rising energy costs, households choose to cook foods that require less preparation and use more processed and prepared foods. These foods are often more expensive per unit and less nutritionally dense than more traditional foods. Food choice is therefore not simply a matter of personal choice, but also of urban design.

The structure of the food retail market also impacts on urban food security. Within SA, as elsewhere, the location of formal food retail is skewed to wealthier areas. In the US and Europe this is known as the food desert phenomenon. A recent University of Cape Town student thesis concluded that the highest-income areas of Cape Town had more than seven times as many supermarkets per 1000 households as the lowest-income areas. Within the food desert phenomenon, the contention is that greater presence of formal retailers will improve 
access to healthier foods. However, it is not clear that this is necessarily the case. It has been suggested that that the entry of the supermarket sector has simply made highly processed foods more spatially and economically accessible. ${ }^{[8]}$ The impact of supermarket expansion on informal traders is not yet well understood, though there have been case studies that suggest that the entry of shopping malls into lowincome areas undermines these small local businesses. ${ }^{[13,14]}$ This may be problematic as the informal sector will offer credit and is often better equipped to sell products in volumes low-income customers can afford. Internationally, fresh produce traders have been found to be more resilient to the entry of supermarkets than other traders. ${ }^{[15]}$ Given the role of both formal and informal food retail in providing food for residents, the structure and location of these markets in the cities need to be considered in urban food security policy. ${ }^{116}$

At the household level, regular and stable income is necessary for food security, but other aspects of the household asset base are also important. For example, limited food storage capacity and refrigeration mean that households are less able to store fresh produce or take advantage of bulk buying, thus limiting dietary diversity. Limited cooking technology means that households tend to buy more processed and prepared foods.

It is the combination of these factors and others that inform patterns of food consumption. This combination of the food environment and what Cannuscio et al. ${ }^{[17]}$ have termed 'food ways' (the social and economic processes involved in the growth, purchase, consumption, sharing, or absence, of food within communities) opens a new space to engage policies and projects to address the nation's nutrition challenges. It is not enough to call for people to make better food choices, when their choices are curtailed by wider structural issues. Even the recent constructive interventions by the state, such as salt regulation and breastfeeding promotion, need to be assessed in the light of the lived realities of poor people. The regulation of salt may not impact the unregulated foodstuffs and food sources on which the urban poor often depend. Likewise, the promotion of breastfeeding through banning the advertising and discounting of formula does not address many of the barriers to breastfeeding that poor women face. They may lack access to maternity leave, onsite childcare, or the facility to store expressed breast milk - all of which are vital to enable mothers to continue breastfeeding. State interventions to address food insecurity and poor nutrition need to be developed with a deeper appreciation of the causes of these nutritional challenges.

There are precedents for the kind of comprehensive approach suggested above. The connections between urban food systems and urban health have been identified and acted upon by major northern cities like Toronto, Canada through their Food Policy Council which reports to the Toronto Board of Health, ${ }^{[18]}$ and New York, USA's FoodWorks programme, which identifies strategic food system interventions as a cost-effective mechanism for addressing NCDs. ${ }^{[19]}$ In Brazil, Belo Horizonte established the Secretariat for Food Policy and Supply in an effort to govern the food system, and facilitate access to nutritious, affordable food to improve urban health. ${ }^{[20]}$

Given the increasing evidence of the health challenges triggered by the changing food system in SA, and with the experience of our urban areas acting as a precursor for the rest of the country - the 'canary down the mine' - it is clear that we need a comprehensive public health approach. This approach needs to move beyond simple nutrition education and food fortification. It should include broad public engagement, and the recognition that the health of the public is a developmental imperative, which requires collective action across a broad front. The medical and health professions need to take a leadership role in building alliances across sectors and disciplines, to foster debate, dialogue and innovation, and to co-create conditions in which healthy and sustainable food choices can be made by everyone.

\section{J Battersby}

African Centre for Cities, University of Cape Town, South Africa

\section{McLachlan}

Division of Human Nutrition, Faculty of Medicine and Health Sciences, Stellenbosch University, South Africa

Corresponding author: J Battersby (jane.battersby.lennard@gmail.com)

1. Nestle, M. Food politics: How the Food Industry Influences Nutrition, and Health. Berkeley: University of California Press, 2002

Patel, R. Stuffed and Starved. The Hidden Battle for the World's Food System. New York: Melville House, 2008.

Shisana O, Labadarios D, Rehle T, et al; SANHANES-1 Team. South African National Health and Nutrition Examination Survey (SANHANES-1). Cape Town: HSRC Press, 2013. http://www.hsrc. ac.za/uploads/pageContent/3893/SANHANES-launch\%20edition\%20(online\%20version).pdf (accessed 4 September 2013).

4. Reddy SP, Resnicow K, James S, et al. Rapid increases in overweight and obesity among South African adolescents: Comparison of data from the South African National Youth Risk Behaviour Survey in 2002 and 2008. Am J Public Health 2012;102(2):262-268. [http://dx.doi.org/10.2105/AJPH.2011.300222] Crush J, Frayne B, McLachlan M. Rapid Urbanization and the Nutrition Transition in Southern Africa: Urban Food Security Series No. 7. Cape Town: African Food Security Urban Network (AFSUN), 2011. http://queensu.ca/samp/afsun/files/AFSUN_7.pdf (accessed 4 September 2013).

6. Drewnowski A, Popkin BM. The nutrition transition: New trends in the global diet. Nutr Rev 1997;55(2):31-43. [http://dx.doi.org/10.1111/j.1753-4887.1997.tb01593.x]

7. Bourne LT, Lambert EV, Steyn K. Where does the black population of South Africa stand on Bourne LT, Lambert EV, Steyn K. Where does the black population of South Africa stand on
the nutrition transition? Public Health Nutr 2002;5(1A):157-162. [http://dx.doi.org/10.1079/ PHN2001288]

8. Igumbor EU, Sanders D, Puoane TR, et al. 'Big Food', the consumer food environment, health, and the policy response in South Africa. PLoS Med 2012;9(7)1-7. [http://dx.doi.org/10.1371/journal. pmed.1001253]

. Beaglehole R, Bonita R, Horton R, et al. Priority actions for the non-communicable disease crisis. Lancet 2011;377(9775):1438-1447. [http://dx.doi.org/10.1016/S0140-6736(11)60393-0]

0. McMichael, P. (2009) A food regime analysis of the 'world food crisis', Agric Human Values 2009;26(4):281-295. [http://dx.doi.org/10.1007/s10460-009-9218-5]

1. Kirsten JF. WP/102 The Political Economy of Food Price Policy in South Africa. Helsinki: UNUWIDER, 2012. http://www.wider.unu.edu/publications/working-papers/2012/en_GB/wp2012-102/ (accessed 4 September 2013).

12. Deans J. Jamie Oliver bemoans chips, cheese and giant TVs of modern day poverty. The Guardian. 27 August 2013. http://www.theguardian.com/lifeandstyle/2013/aug/27/jamie-oliver-chips-cheesemodern-day-poverty (accessed 4 September 2013).

13. Bissiker C. Retailers' drive into the township market threatens spaza shops. Financial Mail. 28 September 2006. http://www.eprop.co.za/index.php/news/item/7487-Retailers-drive-into-thetownship-market-threatens-spaza-shops (accessed 4 September 2013).

14. Ligthelm AA. (2005) Informal retailing through home-based micro-enterprises: The role of spaza shops. Dev South Afr 2005;22(2):199-214. [http://dx.doi.org/10.1080/03768350500163030]

15. Reardon T, Timmer CP, Barrett CB, Berdegue JA. The rise of supermarkets in Africa, Asia and Latin America. Am J Agric Econ 2003;85(5):1140-1146. [http://dx.doi.org/10.1111/j.0092-5853.2003.00520.x] 6. Battersby J. Beyond the Food Desert: Finding ways to speak about urban food security in South Africa. Geogr Ann Ser B 2012;94(2):141-159. [http://dx.doi.org/10.1111/j.1468-0467.2012.00401.x]

17. Cannuscio CC, Weiss EE, Asch DA. The contribution of urban foodways to health disparities. J Urban Health 2010;87(3):381-393. [http://dx.doi.org/10.1007/s11524-010-9441-9]

18. Toronto Food Policy Council. Toronto Food Policy Council 2012 - 2013 Annual Report and Membership Update. http://tfpc.to/news/annual-report-to-the-board-of-health-2012-2013 (accessed 4 September 2013)

19. New York City Council. Foodworks: A Vision to Improve NYC’s Food System. New York: NYCC, 2010. http://council.nyc.gov/downloads/pdf/foodworks_fullreport_11_22_10.pdf (accessed 4 September 2013).

20. Rocha C, Lessa I. Urban governance and food security: The alternative food system in Belo Horizonte, Brazil. International Planning Studies 2009;14(4):389-400. [http://dx.doi. org/10.1080/13563471003642787]

S Afr Med J 2013;103(10):716-717. DOI:10.7196/SAMJ.7463 